\title{
Representações sociais da intergeracionalidade no Boi Brilho do Sesc de São Luís/MA
}

Conceição de Maria Goulart Braga Cuba

\section{SciELO Books / SciELO Livros / SciELO Libros}

CUBA, C. M G. B. Representações sociais da intergeracionalidade no Boi Brilho do Sesc de São Luís/MA. In: D'ALENCAR, R. S., ed. A representação social na construção da velhice [online]. Ilhéus, BA: EDITUS. 2017, pp. 239-274. ISBN: 978-85-7455-486-0. https://doi.org/10.7476/9788574554860.0012.

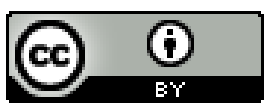

All the contents of this work, except where otherwise noted, is licensed under a Creative Commons Attribution 4.0 International license.

Todo o conteúdo deste trabalho, exceto quando houver ressalva, é publicado sob a licença Creative Commons Atribição 4.0.

Todo el contenido de esta obra, excepto donde se indique lo contrario, está bajo licencia de la licencia Creative Commons Reconocimento 4.0. 


\section{REPRESENTAÇÕES SOCIAIS DA INTERGERACIONALIDADE NO BOI BRILHO DO SESC DE SÃO LUÍS/MA}

Conceição de Maria Goulart Braga Cuba

\section{Iniciando o debate}

A velhice vem sendo historicamente representada como um momento de descanso, inatividade, lazer, mas ao mesmo tempo, as práticas sociais, nas quais as pessoas idosas vêm se engajando, associam essa etapa da vida à participação, aprendizagem, flexibilidade. Isso mostra a relevância de novos estudos sobre os significados da velhice, principalmente das mulheres, que vêm ocupando os espaços públicos das cidades brasileiras.

O presente artigo visa mostrar o significado da presença das mulheres com 60 anos e mais, consideradas idosas pela Organização das Nações Unidas - ONU, nos países de terceiro mundo, no Boi ${ }^{1}$ Brilho do SESC em São Luís, um

1 No Maranhão, é comum e correto denominar essa forma de manifestação cultural como: boi, bumba boi, bumba, bumba meu boi. Utilizarei aqui todos esses termos, que apenas se encontram em maiúsculas quando compreendem nomes próprios e se referirem a um grupo específico e outros casos semelhantes. Também é correto, como utilizo aqui, para me referir ao bumba meu boi - festa, brincadeira, brincar, expressão cultural, manifestação cultural, folguedo, dança de/do boi. 
espaço intergeracional. As idosas envolvidas nas práticas desse grupo interagem com as crianças de seis até doze anos incompletos e adolescentes de doze a dezoito anos de idade, segundo define o Estatuto da Criança e do Adolescente - ECA.

Geração, segundo uma perspectiva sociocultural, aqui significa compartilhar com outros sujeitos do mesmo “[...] grupo de idade, um modo peculiar de socialização, de vivência histórica de determinados momentos do processo sócio-cultural" (GOMES, 2005, p. 109). A intergeracionalidade representa um diálogo entre idosos, crianças e adolescentes, trocando conhecimentos, transmitindo uma memória social, valores, tradição, ritos sociais, que fortalece os vínculos na família e na sociedade, para um agir em conjunto (CUBA, 2015).

A escolha da cultura popular, no âmbito do estudo, não se deu por acaso. Sou maranhense de Guimarães, lugar do Bumba Meu Boi de Zabumba, o sotaque considerado original e vivi nove anos em São Luís. Vale acrescentar que nem na minha infância, em Guimarães, nem na minha juventude, em São Luís, as crianças e as mulheres assistiam a essa festa, pois encerrava de madrugada e com violência. Isso foi na década de 1960, quando, junto a outros jovens, eu dançava a quadrilha em nosso bairro. Vale salientar que, apesar de se apresentar em um bairro próximo, nessa década, o bairro era considerado perigoso e o bumba meu boi significava, entre outros aspectos, espaço de bêbados e de violência. Só os homens assistiam.

Embora frequentemente retorne a São Luís, mas, desta vez, o mês é junho de 2011, período das festas juninas e do bumba meu boi, e o meu cotidiano naquela cidade significava uma pesquisa de Doutorado. Logo na chegada, observo que os tambores ecoam em algum lugar da cidade, não ainda nos arraiais. Nesse momento, relembro os grupos tradicionais, já integrados por homens idosos e jovens mulheres, dançando nos grupos mais recentes, prática impregnada em meu imaginário. 
Os contatos comunicavam sobre os grupos de idosos ludovicenses ${ }^{2}$ em maioria mulheres idosas dos Centros de Convivência, inclusive do Serviço Social do Comércio - SESC-Deodoro, dançando quadrilha e bumba meu boi. Noto que no Boi Brilho do SESC, o espaço é delas. Estimulada e curiosa, inspirei-me na Etnografia para a pesquisa: "Estudo descritivo de um ou mais aspectos sociais e culturais de um povo, grupo social, etc." (FERREIRA, 2008, p. 383). Também, na observação flutuante, criando uma disponibilidade e em um "manter vago", sem me fixar em um objeto preciso, deixei minha observação "flutuar". Essa forma de observar é importante para "[...] que as informações penetrem sem filtro, sem a priori, até o momento em que pontos de referência, de convergências, apareçam e nós chegamos, então, a descobrir as regras subjacentes" (PÉTONNET, 2009, p. 102). Desse modo, assisti no SESCDeodoro a apresentação de vários grupos de bumba meu boi, nos quais, os idosos dançavam junto com seus netos, crianças e adolescentes (CUBA, 2015).

Admirada com a plateia repleta de familiares, amigos e curiosos, como eu, fotografei e filmei essa prática nova e inusitada a quem estava sendo apresentada. Compreendi que essa realidade estranhada e surpreendente é diferente dos grupos tradicionais, onde os sujeitos nascem nas famílias dos boieiros ${ }^{3}$, crescem e envelhecem, passando essa dança a constituir uma prática do seu cotidiano. Além dos grupos apresentados no SESC-Deodoro, identifiquei em vários bairros de São Luís grupos de bumba boi formados por idosos e coordenados por mulheres idosas, assim como a presidente de uma das três Associações de Bumba Meu Boi de São Luís. Por isso, uma questão me

2 Ludovicense é a denominação de quem nasceu ou reside em São Luís, capital do Maranhão.

3 Boieiros são pessoas que integram o grupo de bumba meu boi e que apreciam essa festa. 
instiga: o que representa, principalmente para as mulheres idosas, esse protagonismo, na expressão da cultura do bumba meu boi? Por outro lado, leva-me a questionar: o que representa o agir compartilhado das mulheres idosas com crianças e adolescentes no bumba meu boi criado por idosos?

A cultura neste texto é entendida, em primeiro lugar, como um direito afirmado na Constituição Federal de 1988 e especificado para os idosos no Estatuto do Idoso, no Título II, Dos direitos fundamentais, Capítulo V, da Educação, Cultura, Esporte e Lazer. O Estatuto do Idoso assegura no Artigo $21, \S 2^{\circ}$ que "Os idosos participarão das comemorações de caráter cívico ou cultural, para transmissão de conhecimentos e vivências às demais gerações, no sentido da preservação da memória e da identidade culturais." No Artigo 22 especifica: "Nos currículos mínimos dos diversos níveis de ensino formal serão inseridos conteúdos voltados ao processo de envelhecimento, ao respeito e à valorização do idoso, de forma a eliminar o preconceito e a produzir conhecimentos sobre a matéria” (BRASIL, 2003).

Em segundo lugar, entendo a cultura como possibilidade de enfrentar as desigualdades sociais, manifestando ações de resistência, apesar de legitimar o Estado contemporâneo e perpetuar a ideologia dominante. A cultura consiste em práticas, ideias e sentimentos, expressando relações simbólicas na dimensão do humano e do sagrado "[...] produzidas por grupos que se especializam em diferentes formas de manifestação cultural [...]" (CHAUí, 1985, p. 11). Trata-se de uma cultura socialmente construída que reúne um conjunto de atividades, inclusive ritos e modos simbólicos, sendo transmitida de geração a geração (THOMPSON, 2008). A cultura, uma arena de consensos e de conflito, reúne diferentes formas de diálogo entre: as classes, o escrito e o oral, o campo e a cidade, o antigo e o novo, a tradição e a modernidade. Essa cultura animi faz a mediação do "conflito do artista com o homem de ação", 
assim cuidando e preservando "um mundo de aparências cujo critério é a beleza” (ARENDT, 2002c, p. 272).

Vale salientar que o protagonismo dos idosos pode se expressar em ações abrangentes e coletivas e nas ações individualizadas, em clubes e associações lutando por direitos, no lazer, nos cuidados e outros. Além disso, pode representar "[...] contestação e defesa intransigente dos interesses dos mais velhos contra forças de aniquilamento e dominação, como parceria na construção social, como adesão a micronarrativas individualizantes e hedonistas [...]" e outras (ROZENDO; JUSTO; CORREA, 2010, p. 38).

Na cultura popular, o protagonismo dos idosos junto com as demais gerações constitui um direito afirmado no artigo 215 da Constituição Federal do Brasil de 1988, onde o Estado se responsabiliza em garantir "[...] a todos o pleno exercício dos direitos culturais" (BRASIL, 1988). Em relação às crianças e aos adolescentes, a Convenção Internacional sobre os direitos da criança, visando a proteção desses sujeitos no mundo, foi aprovada na Resolução 44/25 da Assembleia Geral da ONU (20 de nov.1989), também preconizando os direitos das crianças e dos adolescentes. O Brasil foi seu signatário, sancionando em 13 de julho de 1990 o Estatuto da Criança e do Adolescente (ECA), por meio da Lei n. ${ }^{\circ} 8.069$.

Além de afirmar todos os direitos, inclusive a educação, o lazer e a cultura, às crianças e aos adolescentes com "absoluta prioridade", no Capítulo III, Do Direito à Convivência Familiar e Comunitária, Seção I, Disposições Gerais, artigo 19, o Estatuto assegura que

toda criança ou adolescente tem o direito a ser criado e educado no seio da sua família e, excepcionalmente, em família substituta, assegurada a convivência familiar e comunitária, em ambiente livre da presença de pessoas dependentes de substâncias entorpecentes (BRASIL, 1990). 
Desse modo, o Estado também expressa o direito às relações intergeracionais na família e na sociedade a esses sujeitos.

Compartilho com as ideias de Ambrosio (2012) para quem "[...] cuidar é muito mais que um ato, é uma atitude diante da necessidade do outro [...]" e a atitude envolve ocupação, preocupação, responsabilidade e afeto, tendo uma dimensão política arendtiana (AMBROSIO, 2012, p. 302). Entendo que o cuidado está associado, por um lado, à amizade na dimensão de rede de suporte social em que se ajuda nos momentos difíceis, por outro lado, à amizade na dimensão política arendtiana, quando esse vínculo beneficia a comunidade. Isso ocorre porque o exercício político da amizade comporta até mesmo o ato de cuidar do outro (CUBA, 2015), resultando em um cuidado com o mundo, por amor ao mundo (ARENDT, 2002a).

Importa ressaltar que a amizade surge nos espaços de encontros e interações pelo diálogo em comum, é mais ampla que o amor e dele difere. Está associada também à solicitude, ao cuidado e a outros afetos positivos (ABBAGNANO, 1998), que interatuam e se complementam no prazer da companhia mútua do agir. Para Abbagnano: “[...] os afetos constituem a classe restrita de emoções que acompanham algumas relações interpessoais (entre pais e filhos, entre amigos, entre parentes) [...]". Afeto, na visão desse autor, significa proteção, apego, gratidão etc. associados ao cuidado ou preocupação com outra pessoa ${ }^{4}$. Assim, a dimensão política do cuidado e da amizade pode promover bem-estar nos diversos ciclos etários.

$\mathrm{Na}$ busca de tornar familiar o estranhamento latente com a presença das mulheres idosas, das crianças e das adolescentes do Boi Brilho do SESC, desde o estudo de

$4 \quad$ ABBAGNANO op. cit., p. 21. 
2011, busquei aprofundá-lo em 2016, sendo uma parte, aqui apresentada. Entretanto, este texto não se propõe a aprofundar o tema abordado, permanecendo em aberto para novos estudos. No entanto, na intenção de oferecer ao leitor melhor entendimento do texto, além desta introdução, apresento, na segunda seção, um debate sobre dados demográficos e seus relacionamentos com os significados da velhice. Ilustro com alguns relatos de idosas inseridas na Quadrilha da Universidade Integrada da Terceira Idade - UNITI/UFMA, sem me deter em questões da quadrilha.

$\mathrm{Na}$ terceira seção, contextualizo o bumba meu boi maranhense e volto a minha atenção às questões relacionadas à participação das mulheres, inclusive as idosas, e sua interação com as gerações mais jovens, nessa manifestação cultural. Em quarto lugar, apresento brevemente o Boi Brilho do SESC, ilustrando com relatos das mulheres idosas, das crianças e das adolescentes que participam dessa prática social, ressaltando as representações sociais do agir compartilhado nesse grupo. Finalmente apresento as considerações finais.

\section{Representações das mulheres idosas}

Alguns caminhos levam a uma representação social da velhice como, por exemplo, a idade cronológica, demarcando um momento individual. $\mathrm{O}$ aspecto cronológico vem norteando as politicas sociais e o acesso aos direitos sociais dos idosos, mas não consegue definir claramente a idade da velhice brasileira, nem deve ser considerado isoladamente, pela complexidade e heterogeneidade do fenômeno do envelhecimento. Isso porque esse processo também se relaciona a questões de classe, gênero, religião e outras diferenças, além da forma com que cada sujeito envelhece. A sociedade também atribui ao ciclo da velhice 
uma conotação e uma prática peculiares, mostrando estar em aberto o debate sobre o significado da velhice em nosso país. ${ }^{5}$

A demografia referente aos sujeitos com 60 anos ou mais mostra um aumento acelerado que, em 2013, eram 26,1 milhões, e em 2060 espera-se que sejam 33,7\% da população brasileira, se confirmadas as previsões do censo do Instituto Brasileiro de Geografia e Estatística. Em 2010 havia 23,5 milhões de idosos para uma população de 190.732.694 pessoas no Brasil e se esperava que os homens vivessem 58,3 anos de idade e as mulheres 61,8 anos de idade (IBGE, 2010). Isso define a velhice no feminino, pois as mulheres vivem mais que os homens. Em 2013, as idosas eram 55,7\% da população total brasileira. Por outro lado, a população de jovens de 0 a 14 anos de idade diminui gradualmente, sendo esperada, para 2060, uma taxa de 13,0\% de sujeitos da população brasileira nessa faixa etária (IBGE, 2015). Essas constatações mostram a necessidade de eficácia das políticas públicas para o atendimento e proteção social dos idosos, das crianças e dos adolescentes.

São Luís, capital do estado do Maranhão, "cidade por excelência dos sobradões solarengos de fachadas de azulejos" (MEIRELES, 2001, p. 258), onde está situado o SESCDeodoro, lócus da pesquisa de campo, foi fundada em 8 de setembro de 1612 pelo francês Daniel de La Touche, Senhor de La Ravardière e por François de Rasilly ${ }^{6}$. Em 2010, a população desse estado, um dos mais pobres do Brasil, era de 6.574.789 habitantes e de 568.681 idosos (IBGE, 2010), relativo a uma taxa de $8,7 \%$ dos habitantes. Essa cidade de grande desigualdade tinha 1.014.837 habitantes no Censo de 2010 e 77.971 pessoas idosas, ou seja, $7,7 \%$ da sua população. Havia 32.260 homens idosos e 45.711 mulheres idosas.

\footnotetext{
5 Esta seção é ilustrada com relatos de idosas, participantes da pesquisa de Doutorado.

6 MEIRELES, op. cit.
} 
A taxa de pessoas que vivem sós, que em 2010 era de $12,2 \%$ no Brasil, 8,1\% no estado do Maranhão e 9,9\% na população de São Luís, é significativa por estar crescendo rapidamente (IBGE, 2010). Ocorre que viver só, por opção ou por contingências da vida, como independência econômica das mulheres, viuvez, divórcios e outros, vai afetar a prática social dos cuidados, principalmente para as mulheres que vivem mais que os homens. O cuidado aumenta com a idade e revela significativas trocas geracionais, mas pode levar a conflito intergeracional, por exemplo, na convivência das viúvas com familiares, ao cuidarem dos netos (CAMARANO; KANSO; FERNANDES, 2016), mesmo constituindo as mulheres idosas, muitas vezes, importantes provedores financeiros da sua familia.

O cuidado com os netos e outros jovens é expresso na esfera da família, fora dela e no protagonismo das mulheres idosas nos grupos de bumba meu boi em São Luís, por meio de uma amizade intergeracional (CUBA, 2015). Ainda assim, políticas sociais são necessárias também para reverter os preconceitos, estereótipos e estigmas direcionados aos idosos que os denominam de improdutivos, ociosos, disponiveis e outras representações sobre a velhice que impregnam o imaginário social. Isso porque denominações como idoso, terceira idade, melhor idade etc., assimiladas e reelaboradas socialmente, não conseguiram tornar os idosos mais respeitados, diminuir os estereótipos nem difundir uma nova e positiva imagem da velhice (DEBERT, 2004).

Apesar de as mulheres idosas desenvolverem práticas na quadrilha e no bumba meu boi, reinventando a forma de experimentar a sua velhice, modernizando e mostrando um inusitado modo de viver o seu cotidiano, as idosas parecem surpresas com seu próprio protagonismo nessas danças, que requerem agilidade e flexibilidade. Daí, apresentarem questões sobre o seu ciclo de vida, quando o relacionam à idade cronológica, talvez a confrontando em seu imaginário, com suas capacidades e com as representações 
sociais construídas sobre esse momento da vida, como se pode ver no relato de A4, aluna da UNITI/UFMA ${ }^{7}$ :

- Professora, eu tô aqui, mas eu não sou idosa não, viu? Eu tô aqui pra poder fazer meu curso. [...] Professora, eu tô só brincando, mas eu tô prestando atenção na sua conversa (A4, mulher, 57 anos).

Surpreendente esse posicionamento, pois sugere, por um lado, a negação de um significado da velhice impregnado no imaginário social, de descartabilidade do que é velho e valorização do novo, que afeta as relações sociais. Além disso, negar a velhice, aos 57 anos, pode representar, mesmo sem perceber, medo de um futuro de perdas, que contribuem para um isolamento, para reforçar os estereótipos negativos da velhice e a desigualdade entre as gerações no Brasil. Medo esse que parece estar muito presente no imaginário popular, pois uma representação social da velhice isolada, ancorada nas lembranças de ASO3, ex-aluna da UNITI/UFMA, é assim expressa:

- [...] quando eu era menina, a avó era uma pessoa muito velha e que não tinha mais força da palavra na família. [...] A avozinha ficava num canto. [...] Não saía [...] pra lugar nenhum (ASO3, mulher, 70 anos).

Essa representação negativa da velhice também é mostrada nas palavras de A12 (mulher, 61 anos), aluna da UNITI/UFMA, mas revela uma forma de resistência:

- $[\ldots]$ eu não sabia [...] que a gente envelhecia, assim com alegria, $[\ldots]$, com sabedoria. [...] hoje eu já entendo assim o prazer que é até da gente ficar velha. Por que eu

7 Na pesquisa de Doutorado na UNITI/UFMA, denominamos os idosos alunos pela letra da Turma a qual pertencem: A1, B2, C5 por exemplo. $\mathrm{E}$ os ex-alunos, que agora fazem parte de associações, denominamos ASO1, ASO2, ASO3 e assim por diante. 
completei sessenta anos [...] - eu tô com sessenta e um - parecia que eu tava completando quinze, assim, sabe? $[\ldots]$. E [...] antigamente eu tinha medo de ficar velha. [...] velhinha, só dentro de casa [...]. E agora, não. Agora eu sou mais, sei lá, mais alegre. E até com vontade mesmo de viver. Olha, $[. .$.$] já apresentei até Quadrilha [...]. Nunca$ [...] eu fiz isso na minha vida. [...] Eu estou muito feliz.

Certamente feliz com a forma com que a população idosa, principalmente as mulheres que foram educadas para cuidar da esfera privada doméstica, passou a se identificar como protagonista na esfera pública, onde se encontra e se comunica, estabelecendo novos começos. Um dos espaços propiciadores de novos começos, a quadrilha, em São Luís, era dançada tradicionalmente pelos jovens e surgiu dos "encontros de amigos, que buscavam uma forma de se divertir no próprio bairro, durante o período de São João" (REIS, 2003, p. 132). Nesse contexto, o estatuto e a representação social dos sujeitos correspondem ao que diz Arendt:

$\mathrm{Na}$ ação e no discurso, os homens mostram quem são, revelam ativamente suas identidades pessoais e singulares, e assim apresentam-se ao mundo humano, enquanto suas identidades físicas são reveladas, sem qualquer atividade própria, na conformação singular do corpo e no som singular da voz. Esta revelação de "quem", em contraposição a "O que" alguém é - os dons, qualidades, talentos e defeitos que alguém pode exibir ou ocultar - está implícita em tudo o que se diz ou faz (ARENDT, 2002a, p. 192).

A identidade das mulheres idosas é compartilhada nas práticas coletivas e culturais que inventam nas organizações e movimentos de mulheres, nas universidades da terceira idade (UNITI/UFMA), nos Centros de Convivência do Serviço Social do Comércio (SESC) e outros. Espaços públicos em que as idosas se integram a outras gerações tecem amizades e tentam quebrar preconceitos, na busca de sair 
do isolamento e reverter o estigma da velhice. Assim, imprimem novas regras e novos estilos à sua vida, mudando a forma de representação da velhice, pois:

A cada encontro a coletividade mobilizada reitera o que considera serem os scripts da velhice no passado, pondo em ação práticas tidas como inusitadas e que têm a garantia pública de que é possivel e saudável envelhecer sem se confinar aos padrões antigos (DEBERT, 2004, p. 185).

Uma resistência aos padrões antigos é o que parecem mostrar as mulheres idosas em São Luís, em sua performance na quadrilha e no bumba meu boi, onde ganharam uma significativa visibilidade. Aqui, entendo como performance "[...] o conjunto de ingredientes que configuram o ato de acontecer do BMB (bumba meu boi)". Inclui a música, a coreografia, "a dimensão cénica e a dimensão expositiva” (PADILHA, 2014, p. 10).

Para melhor compreensão do objetivo da presente seção, torna-se necessário apresentar o significado do bumba meu boi do Maranhão, como contextualizado a seguir.

\section{Intergeracionalidade no bumba meu boi de São Luís}

Retorno a São Luís, cidade que mantém a forte presença do bumba meu boi, manifestação popular mais expressiva dessa cidade e do estado do Maranhão, para esclarecer que é histórica a participação dos idosos nessa forma de manifestação da cultura, inclusive na plateia, cantando e dançando ao som dos tambores. Essa expressão cultural máxima da cidade foi declarada patrimônio imaterial do Brasil pelo Ministério da Cultura, através do Instituto do Patrimônio Histórico e Artístico Nacional - IPHAN, desde 2011 (SILVA; FERREIRA, 2011). 
Não há consenso na literatura especializada sobre a origem do bumba meu boi no Brasil. Celso de Magalhães e Silvio Romero afirmavam serem as festas populares e o folclore oriundos de Portugal. Para Nina Rodrigues, foram trazidos pelos africanos bantus e pelos sudaneses, representantes dessa prática. O bumba meu boi foi uma festa proibida e passou a ser apresentada mediante autorização policial. Atualmente é marcante na vida dos ludovicenses. Oriunda da classe trabalhadora e um dos elementos centrais na afirmação de uma "maranhensidade", essa tradição é passada de geração a geração (pais para filhos, avós para os netos), na qual os idosos são respeitados como seus guardiões (MARANHÃO, 2011). Tradição, enquanto reatualização de alguns costumes ou cultura (THOMPSON, 2008) e, não, como algo do passado que lá deve permanecer.

O bumba meu boi maranhense é apresentado no mês de junho, seguindo alguns rituais: batizado, apresentação, morte etc. Os grupos de sotaque de Orquestra e de Costa de Mão são formados em sua maioria, por jovens e os poucos idosos são os amos ou donos dos grupos. Os homens e mulheres idosos estão nos grupos tradicionais, como os de sotaque de Zabumba e de Matraca. Atualmente, os grupos vêm incorporando mais os jovens (ALBERNAZ, 2010).

O enredo dessa dança é contextualizado numa fazenda e seu Auto representa uma mulher grávida - Catirina -, companheira do capataz - Pai Francisco, Francisco ou Chico -, que deseja comer a língua do boi mais bonito da fazenda. Ela consegue seu objetivo, satisfazendo assim seu desejo de mulher grávida. O dono da fazenda exige o boi vivo e, após um ritual, o boi renasce e a festa é retomada (ALBERNAZ, 2010).

O sotaque ou estilo do bumba meu boi, que envolve um sistema simbólico, pelo ritmo, sotaque e outras diferenças entre os grupos, é determinado pelo instrumento de percussão principal, a cidade ou região de origem, sen- 
do o bumba meu boi classificado pelo ritmo, indumentária e forma de dançar (ALBERNAZ, 2010). Apesar de controversa, adoto a classificação tradicional dos sotaques apresentada por Reis (2003), que são cinco: Bois da Ilha ou de Matracas ou Pandeirões, Bois de Pindaré e outras regiões ou da Baixada, Bois de Guimarães ou de Zabumba, Bois de Cururupu ou de Costa de Mão, Bois do Munim e imitadores ou de Orquestras. ${ }^{8}$

A brincadeira de boi tem uma questão de gênero, pois foi fundada por homens. Suas mulheres desenvolviam, nos bastidores da brincadeira, atividades domésticas (guardar, preservar, costurar, bordar, cozinhar, preparar indumentárias etc.). Também são madrinhas nos rituais de batismo e morte e desenvolvem outras atividades relevantes para o ritual da festa. Essas posições, apesar de restritas e consideradas secundárias, aproximam-se do cuidado, inclusive indicam poder e prestígio das mulheres nos grupos. Por essa assistência e cuidado prestados por elas aos brincantes nas apresentações, elas foram nomeadas de mutucas ${ }^{9}$ (ALBERNAZ, 2010).

As questões de gênero que influenciam na participação do bumba meu boi se associam às de caráter relacional e do poder, além dos fatores simbólicos que permeiam a construção das relações de gênero. Vinculam-se, assim, às definições de Scott (1990), mostrando a primeira que: "o gênero é um elemento constitutivo de relações sociais fundadas sobre as diferenças percebidas entre os sexos, e o gênero é um primeiro modo de dar significado às relações de poder" (p. 14). E a segunda, dizendo que "o gênero

8 Neste texto, vou me deter mais ao boi de sotaque de orquestra, mais conhecido como Boi de Orquestra, pela aproximação do Boi Brilho do SESC com esse grupo.

9 "Nome das moscas que voam em torno dos bois nos currais do nordeste, por isso o mesmo nome para as mulheres acompanhantes dos boieiros" (ALBERNAZ, 2010, p. 81). 
é um campo no seio do qual, ou por meio do qual, o poder é articulado" (p. 16). Assim, o gênero constitui as relações sociais fundadas sobre as diferenças culturais entre homens e mulheres e integra eixos de desigualdades e poder (SCOTT, 1990).

Isso ocorre, pois enquanto as mulheres cuidam dos homens do bumba meu boi, "para concentrar a força na apresentação", nesses grupos, eles "detêm o poder e o prestígio" e permanecem "como o centro das atenções, mantendo a fama do grupo" (ALBERNAZ, 2010, p. 82). Mesmo assim, na posição de mutuca, relacionada à proteção, as mulheres são enaltecidas e sua posição como acompanhantes dos homens é legitimada. É significativo esse papel das mulheres, no acompanhamento do boi, "pois são filhos, maridos e amigos que, a todo o momento, buscam a sua presença” (TEIXEIRA, 2008, p. 64).

Para Albernaz (2010, p. 89), apesar da "participação mais visivel e expressiva das mulheres", a conotação do folguedo como espaço dos homens parece mantida. Assim é que há papéis (miolo, amo, dirigente etc.) e sotaques (Zabumba, Matraca e Pindaré) tradicionalmente considerados próprios dos homens, cabendo às mulheres "personagens mais leves" (vaqueira, caboclo de fita e índia). E seria o sotaque de orquestra, mais identificado com o feminino (ALBERNAZ; LIMA, 2013, p. 506).

As toadas dos grupos de sotaque de Orquestra ou Bois de Orquestra falam do amor, do bucolismo, dos valores maranhenses ou da história, com mais melodias e poemas e não são associadas à violência como os outros grupos. São acompanhadas por instrumentos de sopro (saxofones, trombones, clarinetas e trompetes), de cordas (banjo e violão) e percussivos (bumbos, tambor onça e maracá), mostrando um perfil singular. A inclusão dos profissionais músicos e seu pagamento trouxe para esse folguedo maranhense a noção dos direitos e obrigações (PADILHA, 2014). 
A visibilidade das mulheres nesse folguedo ocorreu na década de 1970, com a liderança de uma mulher em um grupo. Posteriormente, elas vieram ocupando lugares de destaque, desempenhando todos os papéis nos grupos, no auto ou no cordão, como "[...] brincantes, dançando no cordão, tocando instrumentos, cantando toadas e até exercendo a chefia de alguns conjuntos [...]", e outras tarefas "tidas como femininas" (CARVALHO, 1996, p. 3). Padilha (2014, p. 93) mostra que o Boi de Orquestra abriu caminho, em sua performance, para diversos "grupos sociais, geracionais e de gênero", como crianças, adolescentes e mulheres.

A personagem india, uma das mais antigas, exige das mulheres "uma conformação corporal característica da estética do belo" (ALBERNAZ; LIMA; OLIVEIRA, 2012, p.187). Assim, passam por uma rigorosa avaliação, segundo um critério de representação de beleza, que valoriza uma marca corporal da juventude. Seu comportamento também é observado, pois, em sua maioria, são meninas entre 14 a 25 anos de idade, aceitas nos grupos, apenas com autorização dos seus pais ou dos responsáveis, respeitando o Estatuto da Criança e do Adolescente (ECA) segundo os dirigentes (ALBERNAZ; LIMA, 2013). Trata-se também de um cuidado pela indumentária reduzida usada por elas, que é um diminuto saiote e sutiã ou bustiê, bordado com plumas e canutilhos, perneiras, braçadeiras, colares e arranjos na cabeça. Além da dança em semicírculo, num constante vai e vem em direção ao centro, com frenéticos rebolados e saltos, movimentando os quadris e os ombros (ALBERNAZ; LIMA; OLIVEIRA, 2012).

Os homens, no sotaque de Orquestra, desempenham dois tipos de vaqueiro: campeador e de fita ou rajado. Os vaqueiros usam calça, camisa, saiotes e gola ricamente bordados com miçangas, canutilhos, lantejoulas, perneiras ou polainas e um chapéu com a aba ricamente bordada, com miçangas, canutilhos e lantejoulas. O chapéu dos 
vaqueiros campeadores não possui fitas e sua principal função é dançar com o boi, posicionados em duas fileiras laterais ou em semicírculo, junto com os vaqueiros fitas ou rajados, cuja aba do chapéu tem longas fitas coloridas penduradas (PADILHA, 2014).

Os grupos de sotaque de Zabumba, que confrontam o velho e o novo também congregando diversos idosos e crianças, fortalecem amizades no grupo, representando um "elo de continuidade" (SILVA, 2001 apud SILVA; FERREIRA, 2011, p. 8). Além disso, mantêm aspectos dessa tradição, ao serem compostos por "laços de parentesco e de territorialidades" e isso "implica no repasse dos saberes, possibilitando a continuidade da 'brincadeira', através de várias gerações" (SILVA; FERREIRA, 2011, p. 4). Nesse contexto, além das gerações mais jovens inovarem, atualizarem e preservarem essa festa, isso porque o protagonismo dos avós, junto a seus netos e outros jovens, dialogando e trocando conhecimentos entre passado e presente, tradição e modernidade, contando e recontando os rituais do bumba boi, leva a um registro de memória dos costumes comuns dessa festa. Representa também uma resistência dos idosos e os leva a um sentimento de pertença ao grupo, mantendo "o imaginário do social do Grupo" (TEIXEIRA, 2008, p. 6).

Nos grupos de bumba meu boi de idosos organizados por diversos programas e associações para a terceira idade, os idosos interagem e dançam junto com seus netos e sujeitos de diversas gerações, como no Boi Brilho do SESC, do Trabalho Social com Idosos do SESC-Deodoro em São Luís. 


\section{Idosas, crianças e adolescentes no boi brilho do SESC}

No Brasil, o Serviço Social do Comércio (SESC) é pioneiro no Trabalho Social com Idosos (TSI), criado há mais de 50 anos, desenvolvendo em suas Unidades Operacionais Programas nas áreas da Assistência, Cultura, Educação, Lazer e Saúde, através de Atividades e Projetos. Também é referência no trabalho das relações intergeracionais que envolve idosos, crianças e adolescentes no Brasil.

Em 1989, foi criado o TSI do SESC no Maranhão, integrando o programa Assistência do SESC, visando “[...] elevar a qualidade de vida das pessoas da terceira idade, que nos grupos de convivência da instituição têm a oportunidade de interagir com novas formas de conhecimento, compartilhar expectativas e vivências". Seus integrantes idosos, homens e mulheres, a partir de 60 anos de idade desenvolvem "diversas atividades culturais, sociais, recreativas e esportivas", entre elas: oficinas de dança, música, teatro e o Boi Brilho do $\operatorname{Sesc}^{10}$. A relevância do seu trabalho faz com que o SESC seja reconhecido no estado do Maranhão como referência "[...] na promoção de atividades de integração e socialização para a terceira idade" (SESC MARANHÃO, [200?]).

O Boi Brilho do SESC, coordenado pela assistente social Adalgisa Drumond, foi criado em 1992, pela assistente social que coordenava o grupo e uma professora de Educação Física, junto com os idosos integrantes do Trabalho Social com Idosos do SESC-Deodoro e SESC-Turismo. No início, o boi artefato, confeccionado em um cofo $^{11}$

10 Os outros grupos são: Tambor de Crioula, grupo de Percussão intitulado Percussiva Idade, Banda Sesc Retratos e Canções, Grupo Teatral Pastor do Menino Jesus e Coral Sesc Vozes da Sabedoria.

11 Cofo é um cesto bojudo e de boca estreita confeccionado com uma fibra própria, a embira, e serve para guardar diversos produtos, sendo 
e adornado com papel crepom, apresentava o sotaque de Zabumba, passando ao de Matraca. O número de componentes varia a cada ano pela condição de vulnerabilidade da pessoa idosa. As índias eram as próprias idosas, que, posteriormente, incluíram suas netas, esclareceu a coordenadora do grupo.

Segundo Vovô ${ }^{12}$, o cantador e produtor das coreografias do grupo, esse grupo constitui uma adaptação do Sotaque de Orquestra. Além disso, sobre o significado desse grupo e os papéis que as idosas desempenham:

- Olha, no Boi Brilho do SESC, como em todo bumba boi, [...] é como se fosse uma fazenda. Os Fitas [...] representam os mourãos da fazenda. Eles sempre são colocados pelo lado de fora, em volta do boi. [...]. O vaqueiro campeador - [...] a palavra campear é cuidar, é vigiar o gado no campo. [...] Lá na vida mesmo, ele existe como o vaqueiro que vai buscar [...] a rês desgarrada. Então ele [...] que vai campear o gado, que vai cuidar, que vai vigiar. [...] (VOVÔ).

Sobre a disposição dos personagens em fileiras:

- [...] O [...] boi de Orquestra que é o nosso, [...] dança com duas filas. Uma fila de india, uma fechando também um quadrado. [...] Esse Auto do Bumba Boi tem dois momentos. Durante a temporada, o boi brinca e, quando Catirina tira a língua que o Cazumba vem e [...] reza e o boi ressuscita. […] (VOVÔ).

Vovô esclarece que as idosas representam os vaqueiros campeadores, de acordo com a sua capacidade de dançar:

também usado por pescadores. É chamado também de samburá (FERREIRA, 2008).

12 Ele sugeriu seu próprio nome para constar na pesquisa, além desse, que é como é chamado pelas idosas do grupo, dizendo que gosta de ser chamado assim. Por isso, usei esse. 
- É isso. Porque é uma dança mais frenética, tem que ter mais desenvoltura. Então a coordenação motora tem que estar mais aguçada. [...] Então a gente vai se adaptando e colocando-as, de acordo com a desenvoltura (VOVÔ).

Sobre o personagem indias, esclarece:

- Tem as indias, que a gente conta, porque [...] em anos outros, os homens se juntavam aos indios para poder [...] juntar o gado perdido, porque o indio conhecia mais a mata. Então foi trazido de forma [...] em que nós transformamos em canções, em versos, em prosas, em anedota, o Auto do bumba boi. [...] (VOVÔ).

$\mathrm{Na}$ disposição das fileiras, observa-se que as índias se posicionam ao final do grupo, mas tem um momento, em sua performance, que elas vêm para a frente, entrelaçam-se com as idosas e retornam ao lugar inicial. Sobre isso, assim comenta Vovô:

- Olha, esse é o momento de [...] fusão de idade [...]. A prioridade [...] é das idosas, mas [...] ali é um grupo só. Então, nesse momento, [...] eu faço a junção das idades. Porque as pessoas vão ver que [...] uma senhora com 96 (anos) e uma menina com 13 (anos) dançam no mesmo espaço, que todos têm o mesmo lugar, o mesmo espaço, o mesmo ambiente. [...] que o idoso pode estar em qualquer lugar, dançando com qualquer pessoa (VOVÔ).

Ancorado em sua vivência com o grupo, ele fala de uma intergeracionalidade e da integração das diversas faixas etárias, mostrando uma busca de quebrar preconceitos e estereótipos em relação às mulheres idosas desse grupo, que se apresenta a partir da segunda quinzena de junho em diversos espaços (empresas, hospitais e instituições de longa permanência) e comemorações. Era composto, em 2016, por 86 integrantes, entre eles, mulheres idosas do TSI do SESC no Maranhão, com idades entre 60 a 92 anos além de suas netas e bisnetas, cuja idade mínima é de 6 anos. 
As netas e bisnetas das idosas - Vaqueiros Campeadores e Vaqueiros Fitas - representam o papel de índias, geralmente estimuladas pelas avós e bisavós, mesmo que estas não dancem mais no grupo. São estimuladas também por algumas idosas suas vizinhas, mas só participam mediante autorização dos seus pais e/ou dos seus responsáveis. Não resta dúvida de que o maior número de participantes, a indumentária, a performance e outros atributos façam com que o Boi Brilho do SESC seja o mais conhecido e mais divulgado entre os grupos compostos por idosos, em São Luís (CUBA, 2015).

Segundo as mulheres idosas mais antigas no grupo, até uma determinada época, para entrar no Boi Brilho do SESC, a idosa tinha que ser ou ter sido aluna da UNITI, não havendo mais essa solicitação. No entanto, as idosas, só participam do Boi Brilho do SESC após uma avaliação médica rigorosa. Em 2016, o grupo encontrava-se às sextas-feiras, no turno da manhã, para reuniões, assistir palestras com a equipe interdisciplinar do Trabalho Social com Idosos do SESC-Deodoro. Inclusive, ensaiavam regularmente duas vezes por semana, no período que antecede as festas juninas. Participam também de viagens, passeios, caminhadas, etc., em datas programadas com antecedência. As crianças e as adolescentes só começam a ensaiar quando iniciam suas férias escolares, segundo a coordenadora.

Durante dois meses acompanhei os ensaios e apresentações do Boi Brilho do SESC, realizando observações, reuniões e entrevistas com profissionais vinculados ao TSI do SESC-Deodoro, além de idosos, crianças e adolescentes integrantes do grupo. Ainda fiz fotos e vídeos dos ensaios e das apresentações para complementar as observações. Notei que algumas jovens adultas que se apresentaram como índias nesse grupo desde a infância estão lá e, atualmente, colaboram nos ensaios das índias atuais, como esclareceu a coordenadora. Ao final de dois ensaios, dancei 
no cordão, junto com as idosas, insistentemente convidada e puxada por elas, dada a minha inicial recusa em não me inserir em seu espaço. Ao final, esclareci ao coreógrafo, que entendeu. Em outros momentos, sentei em volta de uma mesa, dialogando com elas sobre assuntos diversos.

Essa forma de interação na pesquisa aproxima-se daquilo que DaMatta, Vasconcellos e Pandolfi (2010, p. 132) chamam de "pesquisa observacional", que "[...] é uma modalidade na qual o pesquisador se torna participante do universo pesquisado, ficando sujeito às mesmas condições dos fatos ou eventos que observa". A interação nesses encontros, trocando gestos, olhares, danças, diálogo e outras formas aprofundou a compreensão do significado da participação dos sujeitos do estudo nesse grupo. Representou também uma maneira de "interagir com o observado no mesmo ambiente e no momento mesmo em que este executa aquilo que é o alvo da própria investigação" (DAMAT TA; VASCONCELLOS; PANDOLFI, 2010, p. 132).

A figura central nesse grupo são as mulheres idosas avós e bisavós - indicando um poder das idosas, ainda que simbólico, na família e na sociedade. O poder se expande para essas esferas, até nas relações de cuidados intergeracionais, e passa a representar um espaço ocupado pelas idosas na manifestação cultural do Boi Brilho do SESC. Isso demarca um novo significado na posição da idade cronológica e parece colocar em cheque o que é ser jovem e o que é ser velho.

Nem novo, nem velho, mas um passado reatualizado pelas mulheres idosas do Boi Brilho do SESC, no encontro entre o passado e o presente geracional, tanto simbolicamente como na ação do cuidado, trocando experiências e fortalecendo laços entre as gerações envolvidas. No relato das crianças e adolescentes, indias do grupo, Madalena e 
Orquídea ${ }^{13}$ residem com uma das suas avós; Violeta reside com uma das bisavós. A avó de Madalena já dançou no Boi Brilho do SESC. A avó de Jade, de Orquídea e a bisavó de Violeta dançam no grupo. No entanto, durante a pesquisa, essas avós e bisavós apenas preencheram o questionário de perfil.

As idosas, as crianças e as adolescentes empenhamse nos ensaios e nas apresentações do grupo, mostrando a relevância de estarem integradas a ele. Para as crianças e as adolescentes é importante participar no grupo, junto com as idosas, pois, segundo a india Ana Carolina, "Eu gosto, porque elas ajudam algumas coisas. Nos passos e na dança".

- Sim, também. Porque, tipo [...] a gente vai ser um dia, elas também, né? Então é importante, sim, porque elas um dia também foram que nem a gente. Foram crianças. É então, a gente [...] brinca com elas, entendeu? [...] (IINDIA MARGARIDA).

- Sim. Porque o idoso é como uma criança. [...] é muito teimoso. [...]. Como eu convivo com minha avó, [...] no cotidiano junto com ela. Às vezes ela tá um dia bom, um dia ruim. [...] mas muitas das vezes, prefere sofrer sozinha. Não quer compartilhar. [...] só [...] quando [...] já não tá mais dando pra segurar. [...]. Muitas vezes, eu converso com a minha avó [...]. A minha relação com ela é muito boa (IINDIA MADALENA).

Ao expressarem suas opiniões, as crianças e as adolescentes relacionam a população idosa com as idosas do grupo do SESC, talvez porque vivenciem essa relação intensamente, nos ensaios e nas apresentações. As crianças e as adolescentes relatam ser importante se relacionarem com os idosos e gostam muito de conversar com suas avós

13 Os nomes das crianças, das adolescentes e das idosas foram trocados para evitar a identificação. 
e bisavós sobre "vários assuntos". Isso representa conhecimento das idosas, troca de experiências, "aprendizado", resgate:

- [...] das histórias que eles contam, de criança. [...] E [...] hoje em dia, nós não temos mais a infância que eles tiveram e eu gosto muito de saber como era antigamente. [...] É ela (avó) que me ajuda em quase todas as situações. [...] Então [...] é assim, um amor verdadeiro que ela tem por mim e que eu tenho por ela (ÍNDIA JADE).

- [...] eles [...], já viveram mais coisas do que a gente. Então se a gente tiver um conflito, [...] que a gente não sabe, eles sabem por que eles [...], de algum modo, já conviveram com aquilo [...] Aprendemos com eles (ÍNDIA VIOLETA).

- [...] Porque [...] não se torna um assunto só de adolescente [...] (mas) entre todos. [...] com o avanço, de muita tecnologia, quase não tem mais conversa entre jovens e jovens, entre idosos e idosos. Então, o único momento que a gente tem pra compartilhar, [...] (é) nas horas das brincadeiras que a gente não tá com o celular na mão [...] as idosas daqui do Boi Brilho do SESC [...] tratam a gente como se fossem as netas delas mesmo [...] (ÍNDIA MADALENA).

Segundo Moragas (2004, p. 135), a transmissão de uma história familiar e social torna os idosos e os avós "referenciais sociais" para as gerações mais novas e uma "âncora situacional”, permitindo que os conflitos sejam solucionados pelo diálogo.

As índias conversam "bastante" com outras idosas no SESC sobre "vários assuntos", principalmente, quando estão sozinhas e antes do ensaio, fazendo: "[...] brincadeiras entre nós [...] amigáveis [...]". Também conversam sobre "[...] a dança, as roupas, [...] a situação da cidade, a politica. [...] (IINDIA JADE). Além disso: “[...] a gente senta pra [...] decidir as coreografias. [...] vai se comunicando (sobre) [...] a roupa, como a gente deve fazer" (ÍNDIA MADALENA).

As indias, como Ana Carolina, ajudam as idosas de diversas formas, inclusive "Nos passos também". Isso é 
considerado importante para elas que até pensam em seu futuro, quando forem idosas. Vejamos: “[...] A gente tem que pensar que um dia, a gente vai estar no lugar deles. Então, a gente tem que tentar (com) a geração em diante, pra fazer isso com a gente [...]" (ÍNDIA MARGARIDA). As demais idosas do grupo: “[...] Muitas das vezes elas pedem pra ajudar na roupa, pra calçar o sapato e eu vou ajudando" (ÍNDIA MADALENA). Além disso, as indias ajudam também a "[...] atravessar uma pista ou com [...] (com o) carrinho de compra, [...] a gente [...] trás eles até aqui (SESC) [...]" (ÍNDIA MARGARIDA).

A índia Madalena acompanhava sua avó para os ensaios: “[...] também pra ajudar [...] a se arrumar e [...] já fui me interessando, né, pela forma como elas eram tratadas, muito bem, aí eu fui gostando [...]" (ÍNDIA MADALENA). Gosta do cuidado institucional direcionado às idosas, tratamento esse que a estimulou a participar do grupo. Há uma amizade entre as indias e as idosas, a quem consideram relevante ajudar, como diz a índia Ana Carolina: "Por [...] que elas precisam de ajuda. Pra aprender os passos". As idosas também ajudam as índias: "Nos passos e na dança" (ÍNDIA ANA CAROLINA). Ao se vestirem também, o: "[...] soutien ${ }^{14}$ que a gente pede pra amarrar [...]" (ÍNDIA MADALENA).

A importância de ajudar os idosos é que possibilita, "principalmente, pra eles": "[...] mais diversão, tentar mais relaxar [...]. Mais saúde [...] (ÍNDIA MARGARIDA). As crianças e as adolescentes se ajudam, além de ajudarem as idosas do SESC. A índia Jade ressalta: "[...] a desigualdade entre os adolescentes e crianças e idosos [...] (em que) eles discriminam elas [...]" (ÍNDIA JADE). Principalmente o desrespeito nos ônibus, não cedendo o lugar da prioridade aos idosos. Diz: "Eu acho isso horrivel. Eu chamo a atenção” (ÍNDIA JADE).

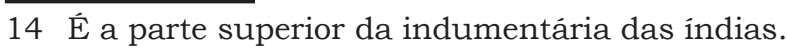


Ao mesmo tempo em que a índia Madalena se sente "[...] feliz pela paciência, [...] do carinho que ela vem me dando, ao longo dos anos" (ÍNDIA MADALENA), preocupase com a avó porque: "[...] pode vir uma depressão. Por isso que é importante eles participarem desses grupos, porque tira as coisas assim da cabeça, pra interagir" (ÍNDIA MADALENA).

Além disso, dançar junto com a avó no Boi Brilho do SESC:

- É muito legal, [...] eu venho toda vez com a minha avó e isso está nos aproximando mais e mais. [...] (Também permite) Fazer novos amigos, conhecer novas pessoas, [...] aprender muitas coisas e conviver com os idosos e [...] outros tipos de pessoa que têm certos tipos de dificuldades (IINDIA JADE).

Entretanto, segundo a índia Jade, a escola, o esporte, a distância da residência e outras atividades dificultam a convivência com sua avó e, "[...] por causa do Boi, nós estamos ficando mais juntas". Por isso, para a índia Violeta, dançar junto com a avó é "um meio de convivência". A india Orquídea relata a importância de acompanhar a avó aos ensaios e às apresentações porque: "[...] quando eu não acompanhava minha avó, ela [...] ia tropeçando em alguma coisa e caía [...]" (ÍNDIA ORQUÍDEA).

Os relatos das índias são críticos e, de forma ética, mostrando a importância do estreitamento dos vínculos de amizade e do cuidado com as idosas, suas avós, e outras participantes do Boi Brilho do SESC, por um lado. Por outro, expressam sua indignação com os problemas enfrentados pela população idosa na sociedade ludovicense, como a desigualdade e o desrespeito. Mesmo ao ressaltar esses problemas, as crianças e as adolescentes revelam um cuidado com as idosas. Na visão arendtiana, esse cuidado significa um cuidado com o mundo, numa dimensão de amor mundi, sendo esse o sentido da política (ARENDT, 2002a). No contexto desse grupo, consiste no alargamento 
da cidadania das idosas, das crianças e das adolescentes, na cultura popular, por meio da interação entre as mães, avós, bisavós, filhas, netas e bisnetas.

Para as mulheres idosas avós e bisavós, é muito importante a convivência com crianças e adolescentes, ainda que netas e bisnetas de outras idosas que não participam do Boi Brilho do SESC. Essa convivência intergeracional, além de um direito, é também:

- [...] um momento em que a gente pode se entrosar com as devidas idades [...] (e) se comunicar com aquele [...] adolescente, transmitir mais conhecimento pra elas [...] É importante.[...] Aprendem a ser mais sociais, fazer novas amizades [...] (AURORA).

Além da "preocupação", enquanto avós, amizade, do prazer em "[...] ver que aquela menina está precisando da gente. [...]" (AURORA). Margarida diz que “[...] é aquela [...] união, [...] todo mundo é família. [...] Ali é neta, bisneta de amigos, é a coisa mais linda do mundo" (MARGARIDA). Além disso, Jasmin acha "muito bonito" as crianças e as adolescentes "pequenininhas [...], uma arrumando a outra" (JASMIN).

- [...] é muito gratificante [...]. É [...] alegria, [...] graciedade, [...] comunicação, [...] brincar com elas, [...] dizendo umas piadas, sorrindo, cantando junto [...] e, às vezes, chamando à atenção também [...]. [...] Quando elas estão brincando, que a gente olha nos olhos delas, [...] sorrindo, tudo alegre, gracejando com um sorriso de orelha a orelha e [...] se sacudindo, [...] a gente se sente feliz [...] (ROSA VERMELHA).

Mesmo não sendo suas netas, Rosa Vermelha também se sente feliz e acha "muito bonito":

- [...] ver o jeito delas [...] interagindo com a gente [...] a integração. [...] cuidado de umas com as outras e nós também como idosas, [...] temos cuidado [...] com (todas as peças da indumentária) [...] Aî [...] eu agarro, ajeito. Então é a felicidade [...] união [...] (ROSA VERMELHA). 
O cuidado é exercitado também pelas idosas e traz felicidade, gratificação, sentimento de utilidade, valorização e outros, na convivência compartilhada com as crianças e as adolescentes. Assim, configura-se como um cuidado mútuo, entre essas faixas etárias. O cuidado institucional é um momento que, para as idosas, "marca muito", pois, em relação à Coordenadora e à Assessora ${ }^{15}$, é a

- [...] preocupação conosco [...] E os rapazes [...] da Banda [...] na porta do ônibus, pegando na mão da gente. (Coordenadora) [...] se preocupa com a alimentação da gente, [...] vigiando pra todo mundo se alimentar naquela [...] distribuição do lanche e [...] (Assessora) também. Então são essas coisas, [...] que a gente sente que a gente é prestigiada [...] (AURORA).

Essa forma de cuidado e de amizade por parte da equipe do Boi Brilho do SESC provoca um sentimento de valorização e de pertencimento ao grupo. As idosas mostram que participar da festa, enquanto nova forma de gestão da velhice, renova a tradicional condição de avó e de bisavó, administrando cuidados aos netos, papéis esperados para mulheres de mais idade (CUBA, 2015). Por outro lado, o cuidado também é associado, sem perceber, no seguinte relato de Vovô: "O Boi também é um médico [...] porque ele cura [...]": "artrite, artrose, osteoporose [...] bota muleta fora, [...] cura dor de cabeça. [...]" (VOVÔ).

Ferrigno (2011, p. 79) entende que os grupos intergeracionais de arte e cultura possibilitam suporte aos idosos, convivência e função social. A cultura popular, enquanto um "contexto alternativo para o encontro de gerações" pode ser uma alternativa viável para revisar a forma como as gerações mais novas percebem as mulheres idosas, fortalecendo laços familiares e sociais. Isso porque:

15 Nomes trocados para evitar a identificação. 
[...] Nas tradições populares os velhos possuem os conhecimentos necessários para a preparação e execução de rituais e eventos festivos de suas comunidades. Por isso são vistos como importantes e são reconhecidos e prestigiados pelos jovens. [...] (No espaço das) festas juninas, entre tantas outras [...] os velhos [...] são muito respeitados pelos mais moços, que muito aprendem com eles (FERRIGNO, 2011, p. 79).

Certamente, pois, como a ação de representar torna familiar algo que se mostra como estranho, mas relevante em seu meio social (MOSCOVICI, 1978), essa festa possibilita às mulheres idosas trazerem à luz práticas familiares de cuidados compartilhados com suas filhas, netas, bisnetas e amigas. Em uma amizade intergeracional na dimensão política arendtiana, as idosas, as crianças e as adolescentes do grupo confrontam ideias, encontram soluções em comum e se percebem pertencendo a uma coletividade. Nesse espaço, as avós e bisavós do Boi Brilho do SESC ressignificam o modo de viver a sua condição humana de mulheres idosas na família e na sociedade, além de fortalecerem elos com suas netas e bisnetas ainda crianças e adolescentes, tão importantes para se manterem em seu contexto familiar e comunitário (RIZZINI et al., 2006).

\section{Considerações finais}

A tradição do bumba meu boi revisitada e reinventada por mulheres idosas do Boi Brilho do SESC reatualiza e preserva a prática social própria a esse coletivo geracional. Essa ação compartilhada com crianças e adolescentes representa um novo começo na tradição do bumba meu boi do Maranhão. Dançar bumba boi em um grupo criado por idosos faz com que essas mulheres boieiras lidem melhor com o seu envelhecimento e consolidem uma representa- 
ção mais positiva da velhice em nossa sociedade. Também permite mostrar que o seu papel tradicional de provedoras dos cuidados com suas netas e bisnetas é um direito que se amplia para o espaço público de São Luís, além de fortalecer vínculos de amizade na família e na sociedade.

Além do mais, as idosas, as crianças e as adolescentes exercitam no grupo um cuidado consigo mesmas e um cuidado compartilhado entre elas, permeado de afetos. Para as idosas, cuidar e serem cuidadas por crianças e adolescentes suas netas e bisnetas, e das suas amigas, no espaço público, revela uma nova estratégia no seu cotidiano de participação de mulheres idosas, cada vez mais ativas e participativas nas ações duráveis desse grupo, em tempos flexiveis. Cuidar e serem cuidadas pelas idosas do grupo, suas avós e bisavós, significa para as crianças e para as adolescentes diálogo, aprendizagem, respeito, alegria, felicidade, maior aproximação entre avós e netas, bisavós e bisnetas. Essa reciprocidade geracional expressa nas apresentações mostra uma nova forma de convivência entre gerações.

Ao comunicarem a história do grupo às crianças e às adolescentes, as idosas reinterpretam e atualizam o passado no presente, reformulando o seu viver cotidiano de mulheres idosas, mães, amigas, avós e bisavós, netas e bisnetas. No agir dialogado nesse espaço de encontro e resgate de memória, essas guardiãs da tradição do grupo do SESC também repassam valores, adquirem novos conhecimentos, são respeitadas e valorizadas. Além disso, em uma forma de resistência social ao preconceito, ao desrespeito, à desigualdade e outros desafios, elas aumentam sua autoestima e melhoram a qualidade da sua vida mais alongada.

Com coragem, apesar das dores e dissabores da vida, nesse grupo, (re)apresentando-o a si mesmas e, aos outros sujeitos, as idosas revelam novas possibilidades de envelhecer e uma identidade alternativa da velhice. Expressan- 
do-se com seu corpo e o som das suas vozes, as idosas, as crianças e as adolescentes lutam pela ampliação de suas cidadanias. Nesse contexto, em que também interagem com a plateia, esses sujeitos politicos conquistam um lugar no mundo plural e comum a todos na cidade de São Luís. Atestam que o envelhecimento é, efetivamente, um processo de todas as gerações, como preconiza a ONU. 


\section{Referências}

ABBAGnANO, N. Dicionário de Filosofia. São Paulo: Martins Fontes, 1998.

ALBERNAZ, S. Mulheres e cultura popular: gênero e classe no bumba-meu-boi do maranhão. Maguaré, n. 24. Bogotá (CO), 2010. p. 69-98. Disponível em:<http:// www.revistas.unal.edu.co/index.php/maguare/article/ view/22736/23551>. Acesso em: 10 jan. 2017.

. LIMA, P. G. B. de. Gênero e cultura popular: relações de poder, posições e significados da participação das mulheres nos grupos de bumba-meu-boi do Maranhão. Sociais e Humanas, v. 26, n. 3, Santa Maria (RS), set./dez 2013, p. 489 - 508. Disponivel em: <https://periodicos.ufsm.br/ sociaisehumanas/article/view/2836/ pdf > . Acesso em: 13 jan. 2017.

. LIMA, P. G; OLIVEIRA, J. M. Maracatus e bumba-bois: onde estão as mulheres? Intratextos. v. 4, n. 1. Rio de Janeiro, 2012. p. 181-200. Disponivel em: <www.e-publicacoes.uerj.br/index.php/intratextos/article/view/2097>. Acesso em: 20 jan. 2017.

AMBROSIO, E. R. Cuidado e família: uma análise compreensiva do modo de caminhar a vida dos cuidadores de idosos. 2012. Tese (Doutorado em Serviço Social) - Pontificia Universidade Católica do Rio de Janeiro, Rio de Janeiro, 2012. Disponivel em: <http://www.maxwell.lambda.ele.puc-rio. br/>. Acesso em: 5 jul. 2013.

ARENDT, H. A condição humana. Trad. Roberto Raposo. 10. ed. Rio de Janeiro. São Paulo: Forense Universitária, 2002a.

. Entre o passado e o futuro. 5. ed. Trad. Mauro W. Barbosa de Almeida. São Paulo: Perspectiva, 2002c.

BRASIL. Constituição (1988). 14. ed. atual. pela EC 40. Rio de Janeiro: DP\&A, 2003. 
BRASIL. Lei n. ${ }^{\circ} 10.741 / 2003$. Dispõe sobre o Estatuto do Idoso. São Paulo: Ed. Escala, 2003.

. Lei . $^{\circ}$ 8069. Dispõe sobre o Estatuto da criança e do adolescente e dá outras providências. Brasília, 13 jul. 1990. Disponivel em: <http://www.planalto.gov. br/ccivil_03/leis/ L8069.htm>. Acesso em: 2 fev. 2016.

CAMARANO, A. A; KANSO, S; FERNANDES, D. Brasil envelhece antes e pós-PNI. In: ALCÂNTARA, A. de O; CAMARANO, A. A.; GIACOMIN, K. C. Politica nacional do idoso: velhas e novas questões. Rio de Janeiro: IPEA, 2016. p. 63-103.

CARVALHO, M. M. P. de. As Mulheres no Bumba-Boi: Saindo detrás das Cortinas. In: Boletim da Comissão Maranhense de Folclore. São Luís - MA: Comissão Maranhense de Folclore, 1996. Disponivel em: <http://www.cmfolclore.ufma. br/arquivos /4f56733221ce61470a012f5b55f55c97.pdf > . Acesso em: 20 mar. 2017, p. 3.

CHAUÍ, M. de S. Politica Cultural. 2. ed. Porto Alegre: Mercado Aberto, 1985.

CUBA, C. de M. G. B. Guarnicê e cidadania na amizade dos idosos cariocas e ludovicenses. São Luís: EDUFMA, 2015.

DAMATTA, R; VASCOCELLOS, J. G M; PANDOLFI, R. Fé em Deus e pé na tábua, ou como e por que o trânsito enlouquece no Brasil. Rio de Janeiro: Rocco, 2010.

DEBERT, G. G. A Reinvenção da velhice: socialização e processos de reprivatização do envelhecimento. São Paulo: EDUSP/Fapesp, 2004.

FERREIRA, A. B. de H. Miniaurélio: o minidicionário da língua portuguesa. 7. ed. Curitiba - PR: Ed. Positivo, 2008.

FERRIGNO, J. C. Programas intergeracionais no Brasil. A terceira idade: estudos sobre envelhecimento. São Paulo: SESC. v. 22, n. 50, p. 74-91, 2011. 
GOMES, M. Q. de C. Temporalidades e relações geracionais: reconstruindo a imagem. In: MOTTA, A. B. da; AZEVEDO, E. L.; GOMES, M. Q. de C. (Org.). Reparando a falta: dinâmica de gênero em perspectiva geracional. Salvador: UNBA, 2005. Disponivel em: <http://www.neim.ufba.br/site/arquivos/file/reparando .pdf>. Acesso em: 25 mar. 2017, p. 99-113.

INSTITUTO BRASILEIRO DE GEOGRAFIA E ESTATÍSTICA. Censo demográfico 2010: características da população e dos domicílios: resultados do universo. Disponível em: <http:// www.ibge.gov.br/cidadesat/topwindow.htm?1>. Acesso em: 20 set. 2016.

. Sintese de indicadores sociais: uma análise das condições de vida da população brasileira, 2015. Disponível em: <http:/ / pt.slideshare.net/LinTrab/sntese-de-indicadoressociais-uma-anlise-das-condies-de-vida-da-populao-brasileira-2015>. Acesso em: 9 mar. 2016.

MARANHÃO. Instituto do Patrimônio Histórico e Artístico Nacional. Complexo cultural do bumba-meu-boi do Maranhão: dossiê do registro como patrimônio cultural do Brasil. São Luís: IPHAN/MA, 2011. Disponivel em:<http://pt.scribd.com/doc/72102630/Bumba-meu-boi-do-Maranhao>. Acesso em: 12 jul. 2012.

MEIRELES, M. M. História do Maranhão. 3. ed. São Paulo: Siciliano, 2001.

MORAGAS, R. M. Gerontologia social: envelhecimento e qualidade de vida. Trad. Nara C. Rodrigues. 2. ed. São Paulo: Paulinas, 2004.

MOSCOVICI, S. A Representação Social da Psicanálise. Rio de Janeiro: Zahar, 1978. 
NACIONES UNIDAS. Plan de Acción Internacional de Viena sobre el Envejecimiento. In: ASAMBLEA MUNDIAL SOBRE EL ENVEJECIMENTO. Viena: Naciones Unidas, 1982. Disponivel em: <http://www.msal.gob.ar/ent/images/ stories / programas/pdf/2013-08_plan-accion-envejecimiento-viena-1982.pdf $>$. Acesso em: 22 fev. 2016.

PADILHA, A. F. de S. A construção ilusória da realidade, ressignificação e recontextualização do bumba meu boi do maranhão a partir da música. 2014. Tese (Doutorado em Música Etnomusicologia) - Universidade de Aveiro. Aveiro - PT, 2014. Disponivel em: <http://ria.ua.pt/handle/10773/13640>. Acesso em: 20 mar. 2017.

PÉTONNET, C. Observação flutuante: o exemplo de um cemitério parisiense. Antropolitica: revista Contemporânea de Antropologia. n. 25, p. 99-111, $2^{\circ}$ sem. 2008. Niterói: EdUFF, 2009.

REIS, J. R. S. dos. São João em São Luís: o maior atrativo turístico-cultural do Maranhão. São Luís: Aquarela, 2003.

RIZZINI, I et al (Coord.). Acolhendo crianças e adolescentes: experiências de promoção de direito à convivência familiar e comunitária no Brasil. 2. ed. São Paulo: Cortez; Brasília: UNICEF; CIESPI; Rio de Janeiro: PUC-Rio. 2006

ROZENDO, A. S; JUSTO, J. S.; CORREA, M. R. Protagonismo politico e social na velhice: cenários, potências e problemáticas. Revista Kairós Gerontologia, São Paulo, v. 13, n. 1, p. 35-52, jun. 2010. Disponivel em: <https://revistas.pucsp.br/ index.php/kairos/article/view/4857>. Acesso em: 4 jan. 2017.

SCOTT, J. Gênero: uma categoria útil de análise histórica. Educação e Realidade, Porto Alegre, v. 16, n. 2, p. 5-22, jul./dez. 1990.

SESC MARANHÃO. Programa Assistência. São Luís: SESC, [200?]. Disponivel em: <http://www.sescma.com.br/exibirPagina.php?id=143\&link=-\&lang=pt>. Acesso em: 20 mar. 2011. 
SILVA, C. B. R; FERREIRA, C. G. S. Ressignificando fronteiras: territorialidade e identidade no Bumba-Meu-Boi do Maranhão. In: Congresso Luso Afro Brasileiro de Ciências Sociais - Diversidades e (des) igualdades, 11., 2011, Salvador. Anais eletrônicos.... Salvador: UFBA, 2011. Disponível em: <http://www.xiconlab.eventos.dype.com.br/resources / Anais/3/1307635760_ARQUIVO_ArtigoLusoAfrosemresumo.pdf>. Acesso em: 13 set. 2012. p. 1-12.

TEIXEIRA, H. M. da C. A festa do Bumba-meu-boi da Maioba na configuração do estilo de vida e lazer. 2008. $124 \mathrm{f}$. Dissertação (Mestrado) - Universidade Estadual Paulista, Rio Claro, 2008. Disponível em: <http:/ / hdl.handle. net/11449/96054>. Acesso em: 16 abr. 2017.

THOMPSON, E. P. Costumes em comum: estudos sobre a cultura popular tradicional. Tradução de Rosaura Echemberg. São Paulo: Companhia das Letras, 2008. 